
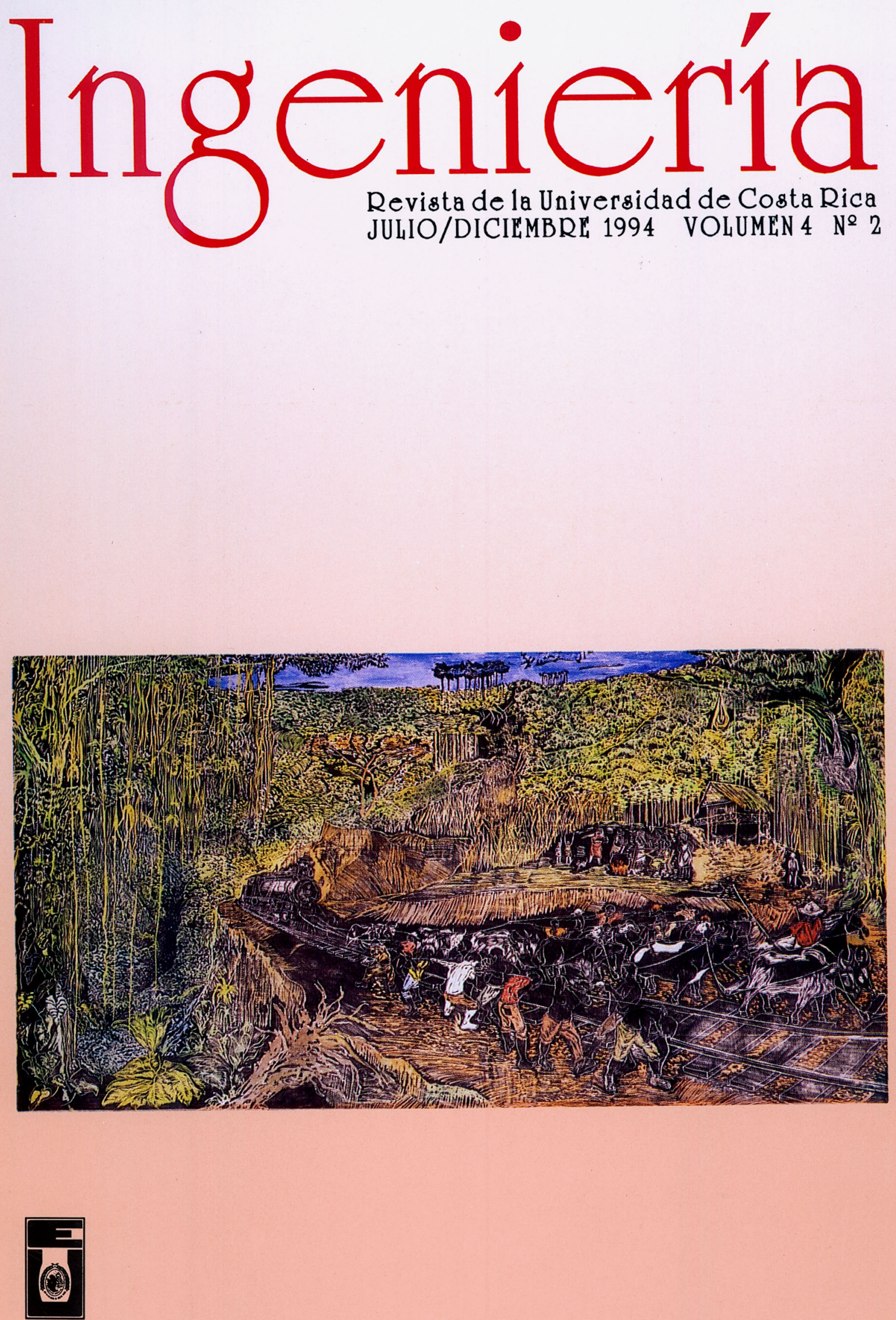


\section{INGENIERO MARTÍN CHAVERRI ROIG: UNA BREVE SEMBLANZA PROFESIONAL}

El ingeniero Martin Chaverri Roig ha sido un profesional importante para la topografía, agrimensura y la geodesia en el país en lo que va del siglo. Retirado de la actividad profesional aún sirve como asesor y consejero intelectual y profesional de muchos ingenieros y organismos de enseñanza de su campo. Intelectual lúcido, 4e amplia cultura, con un acendrado amor por su patria cuya geografía conoce como pocos, nos ha aceptado la sugerencia para que cuente de primera mano las peripecias de las primeras épocas del Instituto Geográfico Nacional y del trazado de los límites de Costa Rica y la hermana república de Panamá, verdadera epopeya de topografía nacional de la época, de la cual fue actor relevante junto con viejos y reconocidos ingenieros de la primera mitad de este siglo, como fueron los ingenieros Ricardo Fernández Peralta, jefe de la Comisión Costarricense de Limites, Federico Guriérrez B. y Mario Barrantes F.

Nació en San José el6 de octubre de 1916. Sus padres fueron el Lic. Tito Chaverri Cordero y Violeta Roig Vargas. Se casó con María Isabel Guevara Umaña con quien procreó seis hijos.

Hizo estudios primarios en la Escuela Buenaventura Corrales y secundarios en el Liceo de Costa Rica en San José. Hizo estudios profesionales mediante Escuelas Internacionales por correspondencia, medio muy usual en aquella época aqui, en los Estados Unidos de Norteamérica yen otras partes del mundo para todos aquellos jóvenes con deseos de estudiar y no tenian una universidad.

Fue incorporado como ingeniero topógrafo en la antigua Facultad de Ingeniería en junio de 1939.

Trabajó primero en agrimensura en la Compañía de Fuerza y Luz de 1940 a 1942. En la Comisión <4: Limites Costa Rica-Panamá desde junio de 1942 a diciembre de 1944.

Al fundarse el Instituto Geográfico Nacional en 1945 comenzó a trabajar como jefe de triangulación. Posteriormente fue jefe de cartografía y desde 1951, jefe de catastro.

Gran luchador por el desarrollo del Catastro participó en muchas actividades en el país y en Centroamérica. Consiguió la ayuda del Gobierno de la República Federal de Alemania en 1965, mediante la cual se formó una comisión técnica y se obtuvieron instrumentos fotográficos y fotogramétricos. Después de que se constituyó el Catastro Fiscal trabajó en Tributación Directa de 1965 a 1967 y luego en el Ministerio de Gobernación para desarrollar un plan piloto de Catastro Juridico. Con la asesoría de la Agencia Internacional del Desarrollo Estadounidense (AID) y la Misión Técnica Alemana se trabajó en la elaboración de una ley de catastro base de la que ahora rige en el Registro Nacional, sede Actual del Catastro.

Fue profesor de la Universidad de Costa Rica en donde dictó cursos en la carrera de perito topógrafo de la Facultad de Ingeniería de 1966 a 1977; también en la Escuela de Topografía y Catastro y Geodesia de la Universidad Nacional de Heredia dictó el curso de Evaluaciones. Actualmente es jubilado desde 1986. Tiene diversas publicaciones sobre topografía y geodesia.

En noviembre de 1978 fue nombrado Miembro Honorario del Colegio Federado de Ingenieros y Arquitectos, en reconocimiento por su labor profesional y de apoyo a la institución de ingenieros del país. Ha ocupado varios puestos en las Juntas Directivas del Colegio de Ingenieros Topógrafos y en el Colegio Federado, así como su participación en diversas comisiones. Desde 1978 es miembro del Consejo Editor del la revista del Colegio.

*Director Revista Ingeniería 